\title{
Financial and Work Burden, Psychosocial Functioning, and Family Interactions During the COVID-19 Pandemic in Indonesia: Effects on Child Outcomes
}

\author{
Yulina Eva Riany ${ }^{1,2}$ [ $\cdot$ Alina Morawska ${ }^{2}$ \\ Accepted: 10 September 2021 / Published online: 20 September 2021 \\ (c) The Author(s), under exclusive licence to Springer Science+Business Media, LLC, part of Springer Nature 2021
}

\begin{abstract}
The COVID-19 pandemic has profoundly affected all aspects of family life worldwide. This study aimed to examine the effects of several family factors on child outcomes during the pandemic in Indonesia, a country with approximately 260 million people. A range of child maladjustment and child competency variables were examined, along with a set of associated variables, including family income, psychosocial functioning, and family interactions, which were modelled via Structural Equation Modelling to understand the interrelationships between variables associated with child adjustment. Using an online survey, a total of 354 parents with at least one typically developing child between the age of 2 and 10 years participated in this study. Results showed that psychosocial functioning and family interactions appeared as successive mediators between family income, financial and work burden, and child adjustment. This study highlights some key concerns to support children's and families' wellbeing during the pandemic in Indonesia.
\end{abstract}

Keywords Financial burden · Psychosocial functioning · Family interactions · Child maladjustment · COVID-19 pandemic

\section{Introduction}

In March 2020, the World Health Organisation (WHO) declared COVID-19 a pandemic disease. It is profoundly affecting lives around the globe. Social distancing, contact restrictions, school, and economic shutdowns have resulted in changes to the psychosocial environment of countries around the world. The current situation significantly affects families and children's daily lives. Kindergartens and schools have been closed, social contacts have been limited, and out-of-home leisure and recreation activities restricted.

Additionally, parents are asked to support their children with "schooling from home" while at the same time working. External support by other family members and social

Yulina Eva Riany

yriany@apps.ipb.ac.id; y.riany@uq.edu.au

Alina Morawska

alina@psy.uq.edu.au

1 Department of Family and Consumer Sciences, IPB University, Bogor, Indonesia

2 Parenting and Family Support Centre, The University of Queensland, Brisbane, Australia support systems have been limited due to health issues. Besides worries and anxieties related to COVID-19, the economic situation has worsened with high and rising levels of unemployment. This situation has put much pressure on children and their families, affecting their wellbeing [1,2].

A similar situation has occurred in Indonesia. Since the Indonesian government declared COVID-19 a national disaster on March 2, 2020, every facet of society has changed dramatically. Indonesians feel threatened by the virus and feel that the government's late response has made them vulnerable to the pandemic [3,4]. Indonesia, with a population of approximately 260 million, has not shown a decline in COVID-19 cases. Data released by the national COVID19 task force in Indonesia indicate dramatically increasing numbers of infection cases with a mortality rate of $5 \%$, and the distribution the cases has increased in all provinces, particularly in areas with high population density such as Jakarta, West Java, or East Java [5]. In other words, there is little indication that this outbreak will end soon in the country.

The Indonesian social-distancing policy to have "working, studying, and praying at home" (3B: Bekerja, Belajar dan Beribadah dari Rumah) has triggered dramatic lifestyle changes for families and individuals across the country. The 
house has become a new centre for all activities of family members, and the conditions might bring changes in families' and children's daily lives. Accordingly, besides focusing on public health, close attention also needs to focus on the effects of the pandemic on family and children's wellbeing.

\section{Child Adjustment During the COVID-19 Pandemic}

Previous studies show that major disasters, including the COVID-19 pandemic, are challenging for child well-being [6-8]. The pandemic not only causes infection and illness at the individual and community level, but the virus also disrupts many essential aspects of human life, including family and children's life [8]. This can result in chronic stress, which can cause wear and tear on the body that may disrupt the development and functions of children over time [7, 9]. In addition, children have experienced separation from parents and loss of parents or other family members to disease, greater food insecurity and lack of access to learning activities due to the pandemic $[8,10]$.

The social restriction policy implemented in the education sector during the pandemic, commonly known as studying from home, has caused additional challenges for children worldwide, including in Indonesia [11, 12]. Although the effects depend on age and the capabilities of the individual child, as well as cultural expectations about the responsibilities or behaviours of children at different ages, challenges in adjusting to day-to-day life, the loss of social and play time or studying together with friends at school, limited opportunities to visit play areas, experiencing firsthand the impact of COVID-19 on parents or their family members (physical, economic, or psychological impacts) and uncertainty of unexpected shocks, are difficult experiences for children. Greater exposure to destruction, loss or illness, displacement or separation from the family due to health issues are linked with acute stress and difficulties in day-to-day functioning among children [7].

A study conducted in China involving 2330 school children has found that children with learning quarantine have shown some signs of emotional distress. Even further research from these observations has shown that $17.2 \%$ of children experienced anxiety, and $22.6 \%$ reported depressive symptoms [13]. A study conducted in Japan with 1200 children indicated that $24.1 \%$ have moderate and $29.3 \%$ have severe mental distress [14]. A similar situation has been found in the United States with $7.1 \%$ of children age 3-17 years old diagnosed with anxiety, and about $3.2 \%$ suffering from depression [15].

In Europe, a study investigating parents' perceptions about their children's behaviour and emotional changes during the pandemic in Italy and Spain has reported that $86.7 \%$ of parents perceive changes in their children [16]. These changes include difficulties in concentration, boredom, irritability, restlessness, nervousness, loneliness, uneasiness, worries, and behavioural disturbances. In Indonesia, a study found that children were at risk for having emotional and behaviour problems [17]. With limited supports, Indonesian children reported having more suicidal thoughts than Thai and Taiwanese children [18]. These findings show evidence that the pandemic brings significant negative impacts on child outcomes, particularly in child maladjustment and family functioning problems worldwide, including in Indonesia. Studies indicated that lack of support, disaster exposure, and negative coping were particular risk factors for chronic mental health concerns among children who experience mass disasters, such as the pandemic COVID-19 [19].

While multiple studies indicate that many children show problems in their emotions and behaviours during the pandemic, it could also be expected that some children show added competencies. It is noted that children's experiences with challenges or adversity act as an essential aspect to promote the development of a child's capacity and skills to handle stressful experiences [20]. During this pandemic, a child's exposure to multiple challenges may bring essential experiences to learn how to be resilient and to cope with their emotions and behaviours [21]. Research focusing on the impacts of mass disasters on children's well-being has shown that resilience is the most significant protective factor for children's mental health problems from trauma experiences [19]. Children's resilience depends on multiple protective factors within families and communities through learning activities, socialization, and available support services $[8,19]$. Numerous studies have indicated that families play a critical role in developing children's resilience and protecting children from trauma following disasters $[7,8,19]$. In addition, learning during quarantine, supported by families may facilitate children to gain better competence through having more time to discover new passions or activities.

The positive and negative changes in child adjustment during the pandemic need to be further explored and possible determinants, including family interactions and psychosocial functioning problems examined. As shown by multiple studies of family interactions [22-24], family factors affect child problems and enhance child competencies. During the pandemic, while the house is a new centre for the family, family factors, specifically family interactions emerge as factors to be examined as potential sources of risk and protection for child outcomes.

\section{Family Interactions During the COVID-19 Pandemic}

Family interactions can be disrupted when parents experience adverse situations [25-27], including having psychosocial functioning problems or financial and work burden [28, 29]. During the COVID-19 pandemic, many families have 
reported experiencing problems related to the economic crisis [30-32] that have affected family interactions [28].

In Indonesia, the COVID-19 pandemic brings pressure, conflicts, and anxiety within families in a context where many Indonesian families are unable to meet their basic needs due to losing their income and employment. In addition, within the Indonesian cultural context, the majority of the employment is in the farming (28.5\%) and service sectors (49.14\%) [33], and the majority of Indonesians have no long-term financial savings. In terms of family responsibilities, although women in Indonesia can forge careers, due to patriarchal values, the husband is usually the sole breadwinner while women take care of domestic duties; therefore, shared household responsibilities are not common within the Indonesian cultural context [34]. This risk of poverty due to lack of family income, in many cases, can lead to an increased likelihood of stress, anxiety, insomnia, and conflict among family members that can decrease mental wellbeing [35-37]. Greater levels of family violence, suicide, or child maltreatment have also been documented during the pandemic [38-40]. We recognise that financial and work burdens can escalate when families face more significant pressure and stress, and the order to stay at home can cause stress and anxiety for those who feel at risk [1, 41]. While parents themselves experience a significant crisis associated with decreasing financial resources and lack of institutional supports, family interactions may also be disrupted. Parents are the key protective factors in children's lives, who are responsible for buffering them against adversity, but may themselves feel overwhelmed by the added stresses of their situation [8].

In addition, during the pandemic, all family members, including parents and children, have to cope with the stress of quarantine and social distancing. Parents and children may feel frustrated, bored, depressed, or irritable during stay-at-home orders. Parents have experienced increased pressure to work from home, keep jobs and businesses running, and be responsible for caring for their children and supervision of schooling children at home at the same time. Notably, parents with low income are not only more likely to work in sectors that have been shut down; also, if their previous job remains open, they are less likely to be able to do it from home and so are more likely to struggle to make it compatible with their additional childcare responsibilities at home [30]. These conditions may appear as an explanation for the lack of connections and less positive interactions among family members caused by significant mental health problems due to the pandemic crisis [37] that may associate with greater child maladjustment.

Research has indicated that parental stress and children's psychological problems due to multiple aspects of the pandemic have significant impacts on children's problems through the mediating role of parental stress [42]. Parents experiencing more stress reported found it challenging to understand their children's needs and to respond positively [43]. Stress among parents is often associated with irritability and difficulties in implementing positive parenting, resulting in a cyclical pattern of negative parent-child interactions and more problematic child behaviour [37, 44]. Parents experiencing more stress may also find it challenging to find more appropriate ways to be responsive and positive to their children; therefore, resulting in a more negative environment for children contributing to more behavioural and emotional problems among children [45].

On the other hand, the pandemic may promote positive interactions among family members. A study indicated that families without financial difficulty reported being able to carry out their work activities from home [30]. These parents reported having space at home to educate their children and to have positive environments and family interactions [30]. During the "stay at home" time, a variety of collaborative family activities, such as eating meals together, playing games, or doing housework together provide the opportunity to support positive family interactions [41], which are expected to impact on reducing child problems and promoting child competencies $[36,46]$.

A survey conducted in Canada involving 3000 parents found that $49.7 \%$ of parents reported experiencing more positive interactions and feeling closer with their children during the pandemic, while $22 \%$ of parents perceived to have more conflicts [26]. While the pandemic brings a negative impact on family relationships, it also can promote family interactions that are expected to affect child competencies. However, it is still unknown to what extent psychosocial functioning problems, financial and work burden have effects, positive or negative, on family interactions and, in turn, on child adjustment in Indonesia.

\section{Financial and Work Burden, Psychosocial Functioning Problems, Family Interaction, and Child Adjustment}

Prior research has found that children's adjustment in adverse situations is affected by the distress levels experienced by parents [47-49]. The links notably indicated that parental mental health problems increase the risk of emotional and behavioural problems in children [50-52].

The Family Stress Model [46] outlines a theoretical process in which economic pressure experienced by parents exacerbates child maladjustment through parental distress, interparental relationship problems, and parenting practice. During the pandemic, family income, financial and work burdens have been reported to affect parental psychosocial functioning problems $[29,53]$ and successively influence child outcomes. The research found that parental lack of financial capacity combined with their responsibilities in 
raising and providing education for their children without institutional support was associated with increasing psychosocial functioning problems [54]. These conditions lead parents to face more difficulties in developing positive interactions and understanding their child's needs in childrearing activities. Stress, anxiety, and psychological problems are often associated with harsh behaviours and difficulties in explaining limits and discipline $[26,28,55]$ and reacting in more hostile and aggressive ways [44].

In Indonesia, among families with low income with financial and work burden, specific supports for parenting and home schooling are less accessible for families during the pandemic [56, 57]. Both parents and children individually may also experience greater stress levels due to more daily hassles, such as lack of access to online learning and other additional tasks. Both parents and children may not have the resources to use online consultations or mental wellbeing support in a safe and confidential environment. The uncertainty about the duration of the COVID-19 pandemic in Indonesia and concerns about family may increase mental health problems. In short, multiple family problems, particularly associated with family income and financial and work burden during the COVID-19 pandemic, may increase child maladjustment among children by having more significant psychosocial functioning problems and fewer positive family interactions.

\section{Current Study}

This study aims to develop and examine a model to explain how factors identified in the literature are associated with child maladjustment and child competency during the pandemic. A set of associated variables, including family income, financial and work burden, psychosocial functioning, and family interactions, were modelled to understand the interrelationships between variables associated with child adjustment.

We hypothesised that psychosocial functioning problems and family interactions act as successive mediators of the relationships between family income, financial and work burden, and child adjustment. Specifically, we predicted that parents with low income would experience higher financial and work burden. These parents would report greater psychosocial functioning problems and have fewer positive interactions within the family, further related to more child maladjustment and fewer child competencies. The hypothesised model is presented in Fig. 1.

\section{Method}

\section{Participants}

Three hundred and fifty-four Indonesian parents of 2-10-year-old children completed the questionnaires. The majority of participants were mothers who were married and only $2.3 \%$ of participants were single mothers. The majority of participants lived on Java Island (i.e. Jabodetabek area, West Java, Central Java, and East Java), and 35.3\% of participants lived outside Java Island (Sumatera, Kalimantan, Sulawesi, Bali, Papua, and Nusa Tenggara). On average, participants age was 36.2 years old $(\mathrm{SD}=6.7)$. Just over a third of participants reported being able to meet their basic expenses despite relatively high levels of education. Detailed participant demographic information is presented in Table 1.

\section{Procedures}

Participants were recruited online through parental online networks, social media (Instagram, Twitter, Facebook, and
Fig. 1 Hypothesized model of relationships between various modifiable parent factors during pandemic COVID-19 associated with Child Adjustment

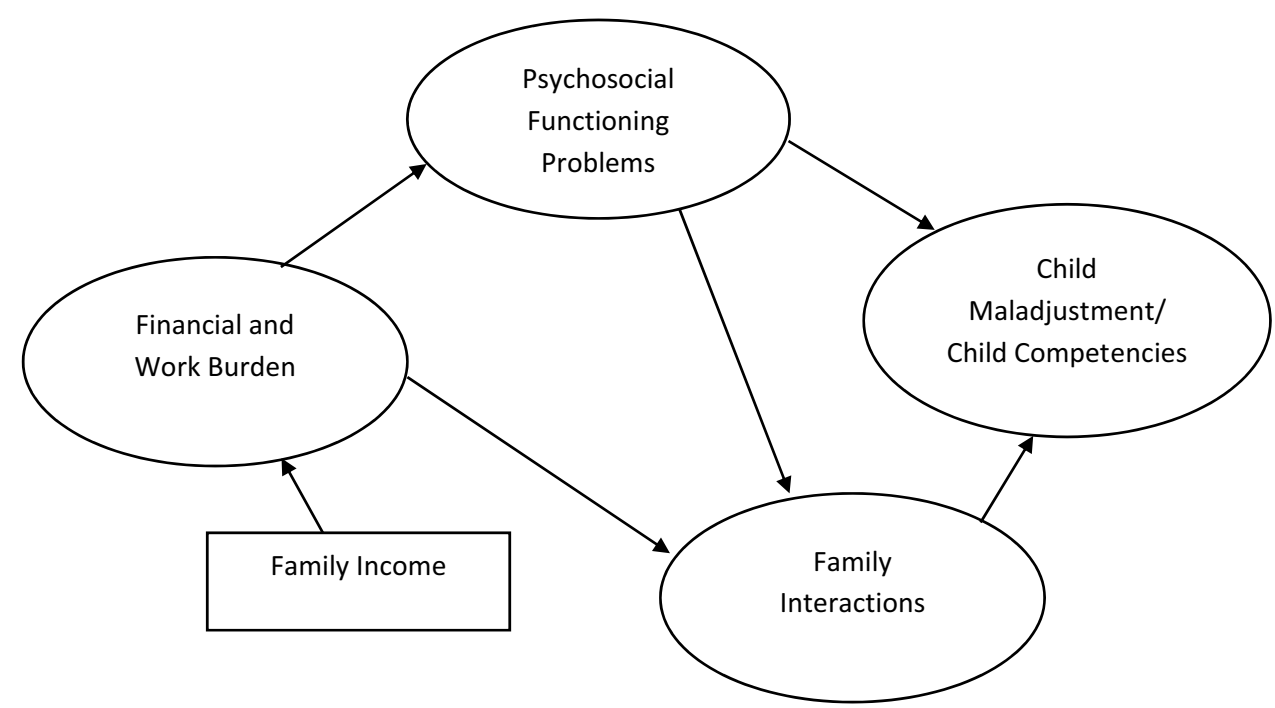


Table 1 Respondents' demographic characteristics

\begin{tabular}{|c|c|c|}
\hline \multirow[t]{2}{*}{ Variables } & \multicolumn{2}{|c|}{$(\mathrm{N}=354)$} \\
\hline & $\mathrm{n}$ & $\%$ \\
\hline \multicolumn{3}{|l|}{ Gender } \\
\hline 1. Male & 78 & 22 \\
\hline 2. Female & 276 & 78 \\
\hline \multicolumn{3}{|l|}{ Marital status } \\
\hline 1. Married & 346 & 97.7 \\
\hline 2. Widowed & 6 & 1.7 \\
\hline 3. Divorced & 2 & 0.6 \\
\hline \multicolumn{3}{|l|}{ Level of education } \\
\hline 1. Primary school or less & 3 & 0.8 \\
\hline 2. High school & 82 & 23.1 \\
\hline 3. Diploma/undergraduate & 195 & 55.1 \\
\hline 4. Post graduate degree & 74 & 20.9 \\
\hline \multicolumn{3}{|l|}{ Occupation } \\
\hline 1. Government employee & 55 & 15.5 \\
\hline 2. Teacher and academic & 122 & 34.5 \\
\hline 3. Private sector & 44 & 12.4 \\
\hline 4. Businessman/businesswomen & 35 & 9.9 \\
\hline 5. Stay home mother/father & 98 & 27.7 \\
\hline \multicolumn{3}{|l|}{ Family income } \\
\hline 1. IDR 0-5 million & 235 & 66.4 \\
\hline 2. IDR 5,01-10 million & 63 & 17.8 \\
\hline 3. IDR $10-50$ million & 52 & 14.7 \\
\hline 4. IDR 50 million and up & 4 & 1.1 \\
\hline \multicolumn{3}{|c|}{$\begin{array}{l}\text { Unable to meet essential expenses (things like food, the mortgage or rent payment, utility bills, child educa- } \\
\text { tion or important medical care during the past } 12 \text { months) }\end{array}$} \\
\hline 1. Yes & 138 & 39.0 \\
\hline 2. No & 201 & 56.8 \\
\hline 3. Not sure & 15 & 4.2 \\
\hline \multicolumn{3}{|c|}{$\begin{array}{l}\text { Left over (Much money left over after paying the essential expenses like food, housing, utilities, child educa- } \\
\text { tion, and medical care) }\end{array}$} \\
\hline 1. Enough and free & 56 & 15.8 \\
\hline 2. Enough for essential needs & 146 & 41.2 \\
\hline 3. Not enough & 152 & 42.9 \\
\hline \multicolumn{3}{|l|}{ Residence } \\
\hline 1. Jabodetabek & 44 & 12.4 \\
\hline 2. West Java & 73 & 20.6 \\
\hline 3. Central Java & 69 & 19.5 \\
\hline 4. East Java & 43 & 12.1 \\
\hline 5. Others (Sumatera, Kalimatan, Sulawesi, Bali, Papua, NTT) & 125 & 35.3 \\
\hline \multicolumn{3}{|l|}{ Child's gender } \\
\hline 1. Male & 150 & 42.4 \\
\hline 2. Female & 204 & 57.6 \\
\hline \multicolumn{3}{|l|}{ Child's school type } \\
\hline 1. Public school & 103 & 29.1 \\
\hline \multirow[t]{2}{*}{ 2. Private school } & 251 & 70.9 \\
\hline & Mean & SD \\
\hline Participant's age & 36.2 & 7.3 \\
\hline Child's age & 6.7 & 2.1 \\
\hline
\end{tabular}

The Family Background Questionnaire [58]

IDR (Indonesian Rupiah); 1 USD=14,500 IDR; 1 AUD = 1,100 IDR 
WhatsApp groups). Participation in this study was voluntary and anonymous. Interested parents were directed to the study webpage, where they were provided with an information sheet and consent form to complete before starting the survey. The online survey was administered using Qualtrics software from August to November 2020. Ethical approval was obtained via The University of Queensland, Australia.

\section{Measures}

The Family Background Questionnaire [58] was administered to collect participant's demographic characteristics, including parent and child age and gender, family composition, marital status, level of education, employment status, and family income. Parents also indicated whether their child has a chronic illness or a physical or developmental disability. Participants in this study were also asked if they currently participate in parenting or therapy programs and we planned to exclude from analyses parents who answered affirmatively to this question, however, zero parents indicated current involvement in any therapy or interventions. Data from parents of a child with a chronic illness or disability were excluded in this study due to different parenting experiences that may affect the analyses.

The Family Well-being Questionnaires during the COVID-19 pandemic (FWQ) is a measure modified from the Families in Australia Survey: The Life during COVID-19 [59]. Modifications were made after obtaining permissions to make the survey more relevant to the Indonesian society context; therefore, questions irrelevant to the Indonesian context (e.g., superannuation, child-care arrangements, the government's allowances, and housework shared activities) were excluded. FWQ consists of 32 items, in three subscales to identify family work and financial burden, psychosocial functioning problems, and family interactions during the pandemic. These include: Financial and Work Burden (15 items; e.g., my workplace is temporarily closed, and I am not getting paid; my family and I have found it challenging to meet our basic expenses (food, house rent, electricity, water, school fee), high scores indicated a high level of financial and work burden experienced by parents during the pandemic. Psychosocial functioning problems consists of nine items measuring psychological problems experienced by parents (e.g., I feel socially isolated; I worry about my own health; I cannot access resources that help me manage my mental health (i.e., therapy, support groups), high scores indicated greater psychological problems experienced by parents due to the pandemic. Family Interactions consists of 8 items (e.g., I have better quality time with my family members; my family members have good interactions) and high scores indicated more positive interactions within family members, particularly parents and children. Each item is rated on a 5-point scale from strongly disagree (1) to strongly agree (5). Subscale scores were obtained by summing the items. Internal consistency in this study is $\alpha=0.79$ for Financial and Work Burden, $\alpha=0.85$ for Psychosocial Functioning Problems, and $\alpha=0.84$ for Family Interactions.

The Child Adjustment and Parent Efficacy Scale (CAPES; [60]) is a measure to assess child wellbeing. This instrument consists of 27 items that form two subscales: Child Maladjustment subscale (e.g., My child yells, shouts or screams; My child seems unhappy or sad) and Child Competency subscale (e.g., My child gets on well with family members; My child can keep busy without constant adult attention). The Child Maladjustment subscale consists of 19 items and the scores ranging from $0-76$, which is made up of behavioural maladjustment score (0-64) (e.g., My child whines or complaints; My child hurts me or others (hits, pushes, scratches, bites)) and emotional maladjustment (0-12) (e.g., My child seems unhappy or sad; My child worries) — higher scores indicating greater child behavioural and emotional maladjustment problems. The child Competency subscale consists of eight items, and scores range from 0-32. Child competency refers to the ability of children to adjust to daily activities and express positive behaviours (e.g., My child follows the rules and limits; My child can do age-appropriate tasks by themselves), with a higher score indicating more positive behaviours) [61]. Participants rate each item on a 4-point Likert scale $(0=$ not true to $3=$ true of my child very much). The total score of each subscale was obtained by calculating the total score of the items. The original instrument demonstrated good validity and internal consistency [61] and it has previously been used in studies of parents in Indonesia [62]. In this study, the internal consistencies were good for the Child Maladjustment subscale $\alpha=0.95$ and the Child Competency subscale $\alpha=0.85$.

\section{Data Analysis}

The data collected were cleaned before analyses, and missing values were dealt with using the impute missing values option. Correlational analyses were initially performed to examine the relationships between demographic characteristics, family financial and work burden, psychosocial functioning, family interactions, child maladjustment (behaviour and emotion), and child competencies.

In evaluating the associations between the constructs and conduct model estimation, Structural Equation Modeling (SEM) was conducted using IBM SPSSTM AMOS 27.0. The primary outcome of interest in our model is child maladjustment and child competence. Parent responses on their financial and work burden, psychosocial functioning, and family interactions were used as indicators of latent constructs included in the model. As family income is strongly associated with financial and work burden and psychosocial 
functioning problems during the pandemic [54, 63], we added family income to the model.

The hypothesised model was tested using maximum likelihood estimation. Model fit was evaluated using the model $\times 2$ statistic, normed $\times 2$ statistic $(\times 2 / \mathrm{df})$, and model fit indices, including root mean square error of approximation (RMSEA), 90\% confidence interval of RMSEA, comparative fit index (CFI), Tucker-Lewis index (TLI), adjusted goodness-of-fit index (AGFI) and standardised root-meansquare residual (SRMR). For the model to be considered an acceptable fit, recommendations are that $\mathrm{p}<0.05$ for the $\times 2$ test, the value of $\times 2 /$ df should be between 1 and 2 , RMSEA and SRMR should be $<0.08$, and CFI, TLI, and AGFI should be $>0.90$.

\section{Results}

\section{Assumptions and Data Screening}

Data were examined to check all assumptions for SEM and to examine the impact of potential outliers. Nine hundred and forty-nine participants had accessed the questionnaire, 493 had not completed any questions so no data is available for them. Of the remaining 456 participants, 29 participants answered the questionnaires related to their child with chronic illness or disabilities and 22 participants had answered a child with age older than 10 years old. Fifty-one participants only provided demographic information and were excluded, leaving 99 with $40 \%$ missing data which was imputed. Imputation technique was employed in this study by replacing each missing value with the mean of the observed values [64]. This resulted in a final sample of 354 participants. The data were screened for univariate outliers and multivariate outliers to meet the criteria for further analyses.

\section{Model Estimation and Evaluation}

Descriptive and correlational analyses were performed using IBM SPSS 27.0. For all of the measures, items were reverse coded when necessary so that a high score indicates a high level of the characteristic being assessed.

Bivariate correlations between demographic characteristics, family financial and work burden, psychosocial functioning, positive family interactions, child maladjustment, and child competency are presented in Table 2 . The results showed moderate to strong correlations among four demographic variables (i.e., level of education, occupation, and family income) and the Financial and Work Burden subscale. Level of education, occupation, family income, and child gender were associated with Psychosocial Functioning Problems. As predicted, the Financial and Work Burden subscale significantly correlated with Psychosocial Functioning Problems and Child Maladjustment. The Family Interactions subscale was associated with Child Competency and negatively correlated with Child Maladjustment, Psychosocial Functioning Problems, and Financial and Work Burden (Table 2).

\section{Procedures}

In analysing the models, all the latent constructs (composite scale scores) were modelled as reflective latent variables,

Table 2 Bivariate correlations between demographic characteristics, family financial and work burden, family functioning, family interactions, child maladjustment, and child competency $(\mathrm{N}=354)$

\begin{tabular}{|c|c|c|c|c|c|c|c|c|c|c|c|c|}
\hline Variables & 1 & 2 & 3 & 4 & 5 & 6 & 7 & 8 & 9 & 10 & 11 & 12 \\
\hline Parent age (1) & 1 & & & & & & & & & & & \\
\hline Parent gender (2) & -.10 & 1 & & & & & & & & & & \\
\hline Child age (3) & $.35 * *$ & -.05 & 1 & & & & & & & & & \\
\hline Child gender (4) & -.02 & .08 & $.11 *$ & 1 & & & & & & & & \\
\hline Level of education (5) & $.13^{*}$ & $-.13^{*}$ & .02 & .01 & 1 & & & & & & & \\
\hline Occupation (6) & $.17 * *$ & $11^{*}$ & -.10 & -.06 & $-.43 * *$ & 1 & & & & & & \\
\hline Family income (7) & -.09 & $-.16^{* *}$ & .08 & -.04 & $.48 * *$ & -.05 & 1 & & & & & \\
\hline Financial and work burden ${ }^{a}(8)$ & -.06 & .03 & -.06 & -.08 & $-.23 * *$ & $.21 * *$ & $-.29 * *$ & 1 & & & & \\
\hline Family functioning problems (9) & -.05 & .08 & -.09 & $-.11^{*}$ & $-.14 * *$ & $.14^{*}$ & $-.11 *$ & $.55^{* *}$ & 1 & & & \\
\hline Family interactions ${ }^{\mathrm{a}}(10)$ & .06 & -.01 & .04 & .02 & $.11^{*}$ & $-.11 *$ & $.11 *$ & $-.13^{*}$ & $-.17 * *$ & 1 & & \\
\hline Child maladjustment $^{\mathrm{b}}(11)$ & -.10 & $.13 *$ & $-.13^{*}$ & -.08 & $-.12 *$ & .07 & $-.13^{*}$ & $.41 * *$ & $.51 * *$ & $-.31 * *$ & 1 & \\
\hline Child competency (12) & .09 & .04 & .06 & .06 & $.11^{*}$ & -.03 & .08 & $-.14 * *$ & -.08 & $.33 * *$ & $-.27 * *$ & 1 \\
\hline
\end{tabular}

*Correlation is significant at the 0.05 level (2-tailed). **Correlation is significant at the 0.01 level (2-tailed)

${ }^{a}$ The Family Well-being Questionnaires during the COVID-19 pandemic [59]

${ }^{\mathrm{b}}$ The Child Adjustment and Parent Efficacy Scale (CAPES) [60] 
i.e., changes in latent constructs were assumed to reflect changes in manifest variables. Our hypothesised models are described in Fig. 1. Model fit was evaluated by considering data from several fit indices to ensure that fit was evaluated fairly and without the temptation to select only the fit indices that provided the best interpretation for the model.

Model 1 acceptably fitted the data, $\chi 2(1372)=3.21$, $\mathrm{p}<0.05, \mathrm{CFI}=0.91$, RMSEA $=0.07$; SRMR $=0.06$. Similarly, model 2 acceptably fitted the data, $\chi 2(896)=3.40$, $\mathrm{p}<0.05, \mathrm{CFI}=0.90 ; \mathrm{RMSEA}=0.07 ; \mathrm{SRMR}=0.07$. The two models showed an acceptable fit to the data and are presented in Figs. 2 and 3. Parental psychosocial functioning problems and family interactions were mediators of the relationships between family income, financial and work burden, and child adjustment. As expected, families with low income experienced more significant problems in finances and work $(r=-0.26, p<0.01)$. Although these parents did not have fewer family interactions, they reported more significant psychosocial functioning problems $(\mathrm{R}=0.40, \mathrm{p}<0.001)$. This was associated with more child maladjustment $(r=0.66$, $\mathrm{p}<0.001$ ) but not related with child competency. As predicted, parental psychosocial functioning problems were linked with family interactions $(\mathrm{r}=-0.18, \mathrm{p}<0.01)$, which then predicted child maladjustment $(r=-0.28, p<0.01)$ and child competency $(r=0.19, \mathrm{p}<0.01)$.

\section{Discussion}

The present study aimed to examine a model to explain how family income, financial and work burden, psychosocial functioning, and family interactions, linked to child maladjustment and child competency during the COVID-19 pandemic in Indonesia. As predicted, Indonesian families with
Fig. 2 Results for the structural equation model of relationships parent factors during pandemic COVID-19 associated with child maladjustment. To simplify the presentation, latent variable indicators and error terms are not shown. Standardized parameter estimates are presented; *p 0.05; **p 0.01; $* * *$ p 0.001 between various modifiable

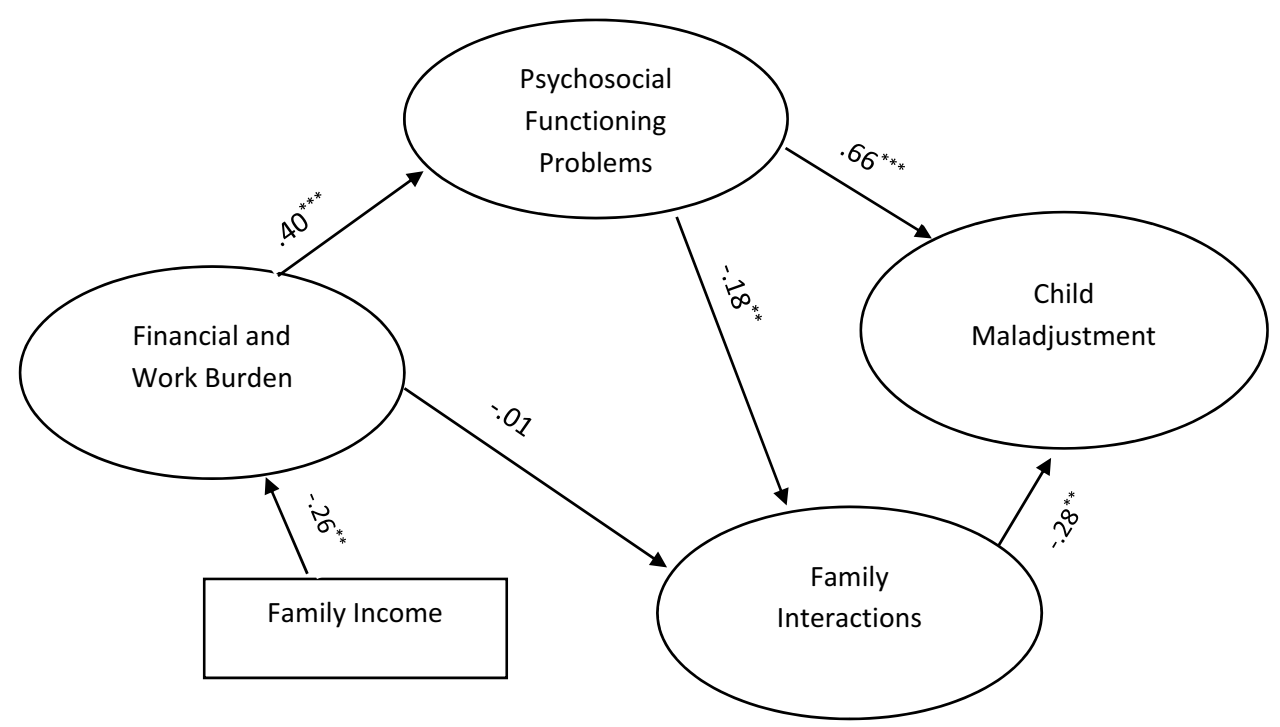

Fig. 3 Final model of relationships between various modifiable parent factors during pandemic COVID-19 associated with child competency. To simplify the presentation, latent variable indicators and error terms are not shown. Standardized parameter estimates are presented; *p 0.05; **p 0.01; $* * *$ p 0.001

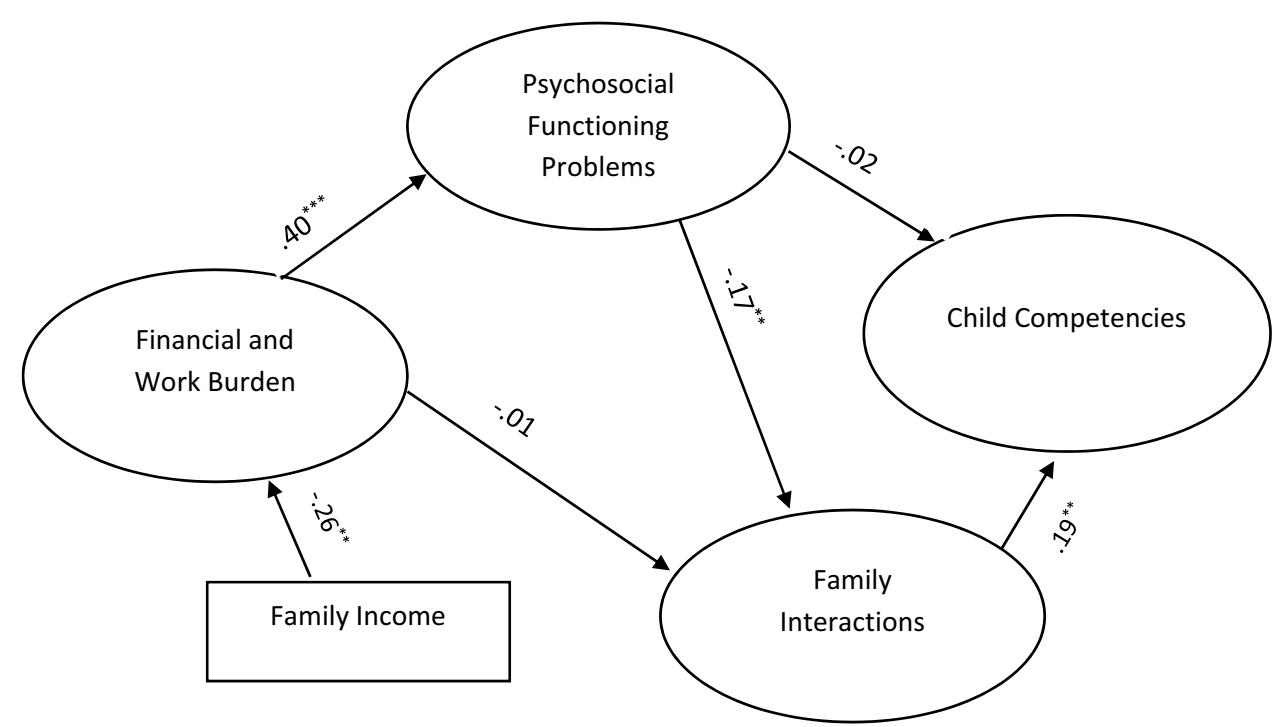


low income reported experiencing financial and work burden during the COVID-19 pandemic. This finding is supported by Indonesian data [65], indicating that approximately 3.05 million employees have lost more than 80 per cent of their family income due to unemployment during the pandemic. In addition, as the majority of Indonesian society work in farming and service sectors with limited savings and financial security, we anticipated that families in Indonesia with low income would experience greater difficulty in financial and work. Many families, particularly those with low financial capacity, probably never expected to experience these significant cuts during this pandemic.

As was anticipated, we found that the Indonesian families with low income exposed to financial and work burden during the COVID-19 pandemic experienced more psychosocial functioning problems. The results support the role of family income and financial difficulties as significant factors related to mental health problems $[28,29,53,66]$. The challenges associated with financial pressure economic recessions due to COVID-19 have implications for many caregivers. The pressure associated with immediate unemployment, income decline, financial insecurity, unmanageable debts, confinement-related stress due to pandemic (e.g., crowding, changes to the structure, and routine) [36, 54], as well as responsibility in caregiving with limited access to specific resources [12, 56, 57], is believed to be an acute threat to family wellbeing. In relation to the situation within the Indonesian cultural context, family well-being may be affected by the great financial pressure from single breadwinners and limited distribution of responsibilities in caregiving within the family due to patriarchal values.

We predicted that parental psychosocial functioning problems would link to child adjustment. In line with the hypothesis, findings indicated that Indonesian parents with psychosocial functioning problems reported greater child maladjustment. This result supported the numerous previous studies that found strong associations between parental mental health (e.g., stress, depression, anxiety mood) and poor child outcomes from infancy through to adolescence [47, 48, 67].

As hypothesised, Indonesian parents who reported psychosocial functioning problems also reported having fewer positive family interactions, which were associated with greater child problems and fewer child competencies. This is in line with previous findings that parental mental health problems resulting from the COVID-19 pandemic could affect daily caregiving activities to be less positive [28], which in turn can result in significant problems (e.g., aggressive, conduct problems, emotional and behavioural problems) among children [44, 53].

One of the main contributions of this study was to link parental psychosocial functioning problems to child outcomes. All were modelled in a framework of the impacts of the pandemic on families and children's wellbeing. Results indicated that the relationship between parental psychosocial functioning problems and child outcomes is complex and not always based on direct effects [68] consistent with the Family Stress Model. While high levels of psychosocial functioning problems were shown to have a direct effect on child maladjustment, low levels of psychosocial functioning problems were not associated with child competencies. The indirect effect of psychosocial functioning problems and child competencies was via the interrelations with family interactions.

On the other hand, when parents' resilience in the adversity was associated with greater positive family interactions, this positive interaction emerged as a protective factor for children was associated with greater child competencies. Extensive studies have shown that positive interactions even in challenging environments were significantly associated with low child maladjustment and better child competencies (see [21, 37, 46, 69]) as found in this study. The ability of the parents to enjoy and appreciate the experience of the parent-child connections during the COVID-19 pandemic may result in less negative consequences on parental psychosocial functioning, and importantly, these have positive implications for child outcomes, specifically on reducing the risks of child maladjustment and increasing child competencies.

As discussed earlier, the COVID-19 health crisis and the resulting social and economic pressure have interacted with child and family wellbeing in Indonesia. As research into the current impacts and longer-term consequences of the pandemic gather pace, an emphasis on the heterogeneity of observed variables could be helpful to support the findings of the study. This research has focused on child and family wellbeing in Indonesia; many other factors could be incorporated into future research to enable a more nuanced understanding of the pandemic stage, life stage, disability and health status, household composition, marital relationships, ethnicity, and social support settings. The current study employed a limited sample size and employed a self-report questionnaire from a single informant that may result in a lack of generalisability and be subject to social desirability biases; large sample sizes with participants from more diverse demographic characteristics from Indonesian society and more objective symptoms measures should be considered in the future to provide more comprehensive and nationally representative findings. The present study involved parents of a child with a wide age range, with differing needs; future studies may include small age ranges of children to indicate how children at different stages of development are affected. For example, while all children would be exposed to increased parental stress, older children may also experience greater difficulties due to reduced peer interactions. In addition, this study mainly focuses on parent factors that influence child adjustment, although the 
reciprocal relationship is also important to consider, with child behaviour, adjustment and wellbeing affecting parents. Finally, future research investigating the reciprocal relationships between parent and child factors during the pandemic is needed.

The findings of this study have implications for the development of policy and legislation concerning child and family wellbeing in Indonesia. It is clear that to reduce the impact of financial and work burden on family and child wellbeing; it is necessary for the Indonesian government to take account of the additional unpaid care burden placed on children and families with low income during the COVID-19 pandemic. Providing "the pandemic aids" which include providing food packages by local government, "pandemic allowance" for low-income families by the Ministry of Social Affairs, "electricity waiver" by the National Electricity Company, and salary waiver for low-income employees by the Ministry of Manpower [70] may help families with a significant financial crisis in dealing with the current situation. Besides, given that the pandemic has affected families and children's mental health, this could be an opportunity for systemic changes that enable mental-care work to be valued and accounted for assisting families and children.

Implementing structured parenting programs that promote positive parenting strategies may reduce child maladjustment and promote child competency by improving family interactions and decreasing psychosocial functioning problems. Such parenting programs are effective in prevention and management of a range of child problems, to improve the capacity of parents, and to reduce parental depression and stress in parenting [71, 72].

In addition, as a positive parent-child relationship through family interactions emerged as a key factor in supporting child adjustment during the pandemic, helping families to have good quality interactions and communication may ultimately facilitate better child mental health [see. 73-76]. Thus, interventions focusing on fostering relationships and communication could be effective to improve the parent-child relationship and promote child adjustment and to support families in Indonesia during and after the pandemic.

\section{Summary}

The present study conducted in Indonesia aimed to examine the effects of family factors on child outcomes during the pandemic. A total of 354 parents with at least one typically developing child between 2 and 10 years completed an online survey. Participants were administered self-report questionnaires to measure a set of associated family variables, including family income, psychosocial functioning, and family interactions, and variables associated with child maladjustment and child competencies. Results showed that psychosocial functioning and family interactions emerged as mediators between family income, financial and work burden, and child adjustment. Indonesia families with low income and financial and work burden were much more likely to report psychosocial functioning difficulties-parents with psychosocial functioning problems perceived fewer positive family interactions and more child maladjustment during the pandemic. Hence, differences in family functioning in response to the pandemic have implications for maladjustment and competencies in children. These findings must be taken into account when designing interventions to support child and family wellbeing during the pandemic in Indonesia.

Author Contributions The Parenting and Family Support Centre is partly funded by royalties stemming from published resources of the Triple P-Positive Parenting Program, which is developed and owned by The University of Queensland (UQ). Royalties are also distributed to the Faculty of Health and Behavioural Sciences at UQ and contributory authors of published Triple P resources. Triple P International (TPI) Pty Ltd is a private company licensed by Uniquest Pty Ltd on behalf of UQ, to publish and disseminate Triple P worldwide. The authors of this report have no share or ownership of TPI. Dr Morawska receives royalties from TPI.TPI had no involvement in the study design, collection, analysis or interpretation of data, or writing of this report. Dr Morawska is an employee at UQ.

Funding This study has no funding.

\section{Declarations}

Conflict of interest The authors declare that all of us have no conflict of interest.

Ethical Approval All procedures performed in studies involving human participants were in accordance with the ethical standards of the institutional and/or national research committee and with the 1964 Helsinki declaration and its later amendments or comparable ethical standards.

Research Involving Human Participants and/or Animals This study has been approved by the Research Ethic Committee of The University of Queensland, Australia.

Informed Consent Informed consent was obtained from all individual participants included in the study.

\section{References}

1. Dong L, Bouey J (2020) Public mental health crisis during COVID-19 pandemic, China. Emerg Infect Dis 26(7):1616-1618

2. Gifford-Smith ME, Brownell CA (2003) Childhood peer relationships: Social acceptance, friendships, and peer networks. J Sch Psychol 41(4):235-284

3. Almuttaqi AI (2020) Kekacauan respons terhadap COVID-19 di Indonesia [The chaotic response to COVID-19 in Indonesia]. The Insights 13:1-7 
4. Bland B (2020) COVID-10 reveals cracks in Indonesia's leadership. Channel News Asia. https://www.channelnewsasia.com/ news/commentary/covid-19-coronavirus-jokowi-indonesia-gover nment-responsehealth-12551876

5. Task Force for the Acceleration of Handling COVID-19 (2020) COVID-19 in Indonesia. covid19.go.id

6. Cobham VE, Newnham EA (2018) Trauma and parenting: considering humanitarian crisis contexts. In: Handbook of parenting and child development across the lifespan. Springer, Cham, pp 143-169

7. Masten AS (2021) Resilience of children in disasters: a multisystem perspective. Int J Psychol 56(1):1-11

8. Masten AS, Motti-Stefanidi F (2020) Multisystem resilience for children and youth in disaster: reflections in the context of COVID-19. Advers Resil Sci 1(2):95-106

9. McEwen BS (2020) A life-course, epigenetic perspective on resilience in brain and body. In: Stress resilience. Academic Press, New York, pp 1-21

10. Ambrose AJH (2020) Inequities during COVID-19. Pediatrics $146(2): 1-5$

11. Fong V, Larocci G (2020) Child and family outcomes following pandemics: a systematic review and recommendations on COVID19 policies. J Pediatr Psychol 45(10):1124-1143

12. Riany YE (2021) Strategi dan tantangan pengasuhan anak di Indonesia [Parenting strategi and challenges in Indonesia]. Rajawali Pers, Depok

13. Xie X, Xue Q, Zhou Y, Zhu K, Liu Q, Zhang J, Song R (2020) Mental health status among children in home confinement during the coronavirus disease 2019 outbreak in Hubei Province, China. JAMA Pediatr 174(9):898-900

14. Horiuchi S, Shinohara R, Otawa S, Akiyama Y, Ooka T, Kojima $R$ et al (2020) Caregivers' mental distress and child health during the COVID-19 outbreak in Japan. PLoS ONE 15(12):e0243702

15. Centers for Disease Control and Prevention (CDC) (2020) Anxiety and depression in children: Get the facts. https://www.cdc.gov/ childrensmentalhealth/features/anxiety-depression-children.html

16. Orgilés M, Morales A, Delvecchio E, Mazzeschi C, Espada JP (2020) Immediate psychological effects of the COVID-19 quarantine in youth from Italy and Spain. Front Psychol 11:1-10

17. Wiguna T, Anindyajati G, Kaligis F, Ismail RI, Minayati K, Hanafi E et al (2020) Brief research report on adolescent mental wellbeing \& school closures during the COVID-19 pandemic in Indonesia. Front Psych 11:1-9

18. Pramukti I, Strong C, Sitthimongkol Y, Setiawan A, Pandin MGR, Yen CF et al (2020) Anxiety and suicidal thoughts during the COVID-19 pandemic: cross-country comparative study among Indonesian, Taiwanese, and Thai University Students. J Med Internet Res 22(12):e24487

19. Lai BS, Lewis R, Livings MS, La Greca AM, Esnard AM (2017) Posttraumatic stress symptom trajectories among children after disaster exposure: a review. J Trauma Stress 30(6):571-582

20. Masten AS (2015) Ordinary magic: resilience in development. Guilford Publications, New York

21. Dvorsky MR, Breaux R, Becker SP (2020) Finding ordinary magic in extraordinary times: child and adolescent resilience during the COVID-19 pandemic. Eur Child Adolesc Psychiatry. https://doi.org/10.1007/s00787-020-01583-8

22. Barger MM, Kim EM, Kuncel NR, Pomerantz EM (2019) The relation between parents' involvement in children's schooling and children's adjustment: a meta-analysis. Psychol Bull 145(9):855-890

23. Longmore MA, Manning WD, Giordano PC (2013) Parent-child relationships in adolescence. In: Fine MA, Fincham FD (eds) Handbook of family theories: a content-based approach. Routledge/Taylor \& Francis Group, London, pp 28-50
24. Sentse M, Laird RD (2010) Parent-child relationships and dyadic friendship experiences as predictors of behavior problems in early adolescence. J Clin Child Adolesc Psychol 39(6):873-884

25. Cluver L, Lachman JM, Sherr L, Wessels I, Krug E, Rakotomalala $S$ et al (2020) Parenting in a time of COVID-19. Lancet 395(10231):e64

26. Gadermann AC, Thomson KC, Richardson CG, Gagné M, McAuliffe C, Hirani S, Jenkins E (2021) Examining the impacts of the COVID-19 pandemic on family mental health in Canada: findings from a national cross-sectional study. BMJ Open 11(1):1-11

27. Lee SJ, Ward KP (2020) Research brief: stress and parenting during the coronavirus pandemic. University of Michigan Parenting in Context Research Lab, Ann Arbor

28. Lawson M, Piel MH, Simon M (2020) Child maltreatment during the COVID-19 pandemic: consequences of parental job loss on psychological and physical abuse towards children. Child Abuse Neglect 110:104709

29. Russell BS, Hutchison M, Tambling R, Tomkunas AJ, Horton AL (2020) Initial challenges of caregiving during COVID-19: caregiver burden, mental health, and the parent-child relationship. Child Psychiatry Hum Dev 51(5):671-682

30. Blundell R, Costa Dias M, Joyce R, Xu X (2020) COVID-19 and inequalities. Fisc Stud 41(2):291-319

31. Brown SM, Doom JR, Lechuga-Peña S, Watamura SE, Koppels $\mathrm{T}$ (2020) Stress and parenting during the global COVID-19 pandemic. Child Abuse Negl 110:1-14

32. Power K (2020) The COVID-19 pandemic has increased the care burden of women and families. Sustain: Sci Pract Policy 16(1):67-73

33. Badan Pusat Statistik (Statistic Indonesia) (2020) Statistics Indonesia. Jakarta. www.bps.go.id

34. Riany YE, Meredith P, Cuskelly M (2017) Understanding the Influence of traditional cultural values on Indonesian parenting. Marriage Fam Rev 53(3):207-226. https://doi.org/10.1080/01494 929.2016.1157561

35. Frasquilho D, Matos MG, Salonna F, Guerreiro D, Storti CC, Gaspar T, Caldas-de-Almeida JM (2015) Mental health outcomes in times of economic recession: a systematic literature review. BMC Public Health 16(1):1-40

36. Prime H, Wade M, Browne DT (2020) Risk and resilience in family well-being during the COVID-19 pandemic. Am Psychol 75(5):631-643

37. Spinelli M, Lionetti F, Pastore M, Fasolo M (2020) Parents' stress and children's psychological problems in families facing the COVID-19 outbreak in Italy. Front Psychol 11:1-7

38. Catani C, Jacob N, Schauer E, Kohila M, Neuner F (2008) Family violence, war, and natural disasters: a study of the effect of extreme stress on children's mental health in Sri Lanka. BMC Psychiatry 8(1):1-10

39. Seddighi H, Salmani I, Seddighi S (2020) Saving lives and changing minds with Twitter in disasters and pandemics: a literature review. Journal Media 1(1):59-77

40. Yoshikawa H, Wuermli AJ, Britto PR, Dreyer B, Leckman JF, Lye SJ et al (2020) Effects of the global coronavirus disease-2019 pandemic on early childhood development: short-and long-term risks and mitigating program and policy actions. J Pediatr 223:188-193

41. Li W, Yang Y, Liu ZH, Zhao YJ, Zhang Q, Zhang L et al (2020) Progression of mental health services during the COVID-19 outbreak in China. Int J Biol Sci 16(10):1732-1738

42. Cusinato M, Iannattone S, Spoto A, Poli M, Moretti C, Gatta M, Miscioscia M (2020) Stress, resilience, and well-being in Italian children and their parents during the COVID-19 pandemic. Int J Environ Res Public Health 17(22):8297-8301

43. Scaramella LV, Neppl TK, Ontai LL, Conger RD (2008) Consequences of socioeconomic disadvantage across three generations: 
parenting behavior and child externalizing problems. J Fam Psychol 22(5):725-737

44. Pinquart M (2017) Associations of parenting dimensions and styles with externalizing problems of children and adolescents: an updated meta-analysis. Dev Psychol 53:873-932. https://doi. org/10.1037/dev0000295

45. Masten AS (2001) Ordinary magic: resilience processes in development. Am Psychol 56(3):227-238

46. Szabo TG, Richling S, Embry DD, Biglan A, Wilson KG (2020) From helpless to hero: promoting values-based behavior and positive family interaction in the midst of COVID-19. Behav Anal Pract 13(3):568-576

47. Conway A, McDonough SC, MacKenzie MJ, Follett C, Sameroff A (2013) Stress-related changes in toddlers and their mothers following the attack of September 11. Am J Orthopsychiatry 83(4):536-544

48. Masarik AS, Conger RD (2017) Stress and child development: a review of the family stress model. Curr Opin Psychol 13:85-90

49. Riany YE, Haslam D, Sanders M (in press) Parental mood, parenting style and child emotional and behavioural problems: AustraliaIndonesia cross-cultural study. J Child Fam Stud

50. Baker BL, Blacher J, Olsson MB (2005) Preschool children with and without developmental delay: behaviour problems, parents' optimism and well-being. J Intellect Disabil Res 49(8):575-590

51. Hails KA, Reuben JD, Shaw DS, Dishion TJ, Wilson MN (2018) Transactional associations among maternal depression, parentchild coercion, and child conduct problems during early childhood. J Clin Child Adolesc Psychol 47(sup1):S291-S305

52. Villodas MT, Bagner DM, Thompson R (2018) A step beyond maternal depression and child behavior problems: the role of mother-child aggression. J Clin Child Adolesc Psychol 47(4):634-641

53. Wanberg CR, Csillag B, Douglass RP, Zhou L, Pollard MS (2020) Socioeconomic status and well-being during COVID-19: a resource-based examination. J Appl Psychol 105(12):1382-1396. https://doi.org/10.1037/apl0000831

54. Fegert JM, Vitiello B, Plener PL, Clemens V (2020) Challenges and burden of the Coronavirus 2019 (COVID-19) pandemic for child and adolescent mental health: a narrative review to highlight clinical and research needs in the acute phase and the long return to normality. Child Adolesc Psychiatry Ment Health 14:1-11

55. Riany YE (2016) Parenting style and parent-child relationships of Indonesian parents of children with and without autism spectrum disorder (ASD). Doctoral Dissertation. The University of Queensland, Brisbane, Australia

56. Putra P, Liriwati FY, Tahrim T, Syafrudin S, Aslan A (2020) The students learning from home experiences during Covid-19 school closures policy in Indonesia. Jurnal Iqra': Kajian Ilmu Pendidikan 5(2):30-42

57. Putri RS, Purwanto A, Pramono R, Asbari M, Wijayanti LM, Hyun CC (2020) Impact of the COVID-19 pandemic on online home learning: an explorative study of primary schools in Indonesia. Int J Adv Sci Technol 29(5):4809-4818

58. Sanders MR, Morawska A (2010) Family Background Questionnaire (FBQ). Parenting and Family Support Centre, The University of Queensland, St Lucia

59. Australian Institute of Family Studies Survey (2020). Life during COVID-19. https://aifs.gov.au/fia-survey

60. Morawska A, Sanders MR (2010) The child adjustment and parent efficacy scale (CAPES). Parenting and Family Support Centre, Brisbane

61. Mejia A, Filus A, Calam R, Morawska A, Sanders MR (2016) Validation of the Spanish version of the CAPES: a brief instrument for assessing child psychological difficulties and parental selfefficacy. Int J Behav Dev 40(4):359-372

62. Sumargi A, Sofronoff K, Morawska A (2015) A randomizedcontrolled trial of the Triple P-Positive Parenting Program Seminar Series with Indonesian parents. Child Psychiatry Hum Dev 46(5):749-761. https://doi.org/10.1007/s10578-014-0517-8

63. Sanmugam A, Vythilingam G, Singaravel S, Nah SA (2020) Assess, adapt and act: a paediatric surgery division's initial approach in a rapidly evolving pandemic. Pediatr Surg Int 36(8):925-931

64. Schneider T (2001) Analysis of incomplete climate data: estimation of mean values and covariance matrices and imputation of missing values. J Clim 14(5):853-871

65. Kompas.com (2020) Bersiap Menghadapi Puncak Pandemi Covid19 di Indonesia Halaman all-Kompas.com. 29 Apr 2020

66. Ornell F, Schuch JB, Sordi AO, Kessler FHP (2020) "Pandemic fear" and COVID-19: mental health burden and strategies. Braz J Psychiatry 42(3):232-235

67. Sweeney S, MacBeth A (2016) The effects of paternal depression on child and adolescent outcomes: a systematic review. J Affect Disord 205:44-59

68. Romero E, López-Romero L, Domínguez-Álvarez B, Villar P, Gómez-Fraguela JA (2020) Testing the effects of COVID-19 confinement in Spanish children: the role of parents' distress, emotional problems and specific parenting. Int J Environ Res Public Health 17(19):1-23

69. Gurwitch RH, Salem H, Nelson MM, Comer JS (2020) Leveraging parent-child interaction therapy and telehealth capacities to address the unique needs of young children during the COVID19 public health crisis. Psychol Trauma Theory Res Pract Policy 12(S1):s82-s84

70. Kompas.com (2020) Ada Tujuh Bantuan Pemerintah Selama Pandemi COVID-19. Halaman all-Kompas.com. 26 Aug 2020

71. Morawska A, Haslam D, Milne D, Sanders MR (2011) Evaluation of a brief parenting discussion group for parents of young children. J Dev Behav Pediatr 32(2):136-145. https://doi.org/10. 1097/DBP.0b013e3181f17a28

72. Sanders MR, Kirby JN, Tellegen CL, Day JJ (2014) Towards a public health approach to parenting: a systemtic review and metaanalysis of the Triple P-Positive Parenting Program. Clin Psychol Rev 32:337-357. https://doi.org/10.1016/j.cpr.2014.04.003

73. Abel MR, Hambrick EP, Vernberg EM (2021) Talking with children about natural disasters: maternal acknowledgment, child emotion talk, and child posttraumatic stress symptoms. In: Child \& youth care forum. Springer, Berlin, pp 1-22

74. Bountress KE, Gilmore AK, Metzger IW, Aggen SH, Tomko RL, Danielson CK et al (2020) Impact of disaster exposure severity: cascading effects across parental distress, adolescent PTSD symptoms, as well as parent-child conflict and communication. Soc Sci Med 264:1-9

75. Cobham VE, McDermott B, Haslam D, Sanders MR (2016) The role of parents, parenting and the family environment in children's post-disaster mental health. Curr Psychiatry Rep 18(6):53-65

76. Overbeek MM, Koren-Karie N, Ben-Haim AE, de Schipper JC, Dreier Gligoor PD, Schuengel C (2019) Trauma exposure in relation to the content of mother-child emotional conversations and quality of interaction. Int J Environ Res Public Health 16(5):1-15

Publisher's Note Springer Nature remains neutral with regard to jurisdictional claims in published maps and institutional affiliations. 